Article

\title{
Carboxymethyl Cellulose-Grafted Mesoporous Silica Hybrid Nanogels for Enhanced Cellular Uptake and Release of Curcumin
}

\author{
Neha Tiwari ${ }^{1,2}$, Laxman Nawale ${ }^{3}$, Dhiman Sarkar ${ }^{2,3}$ and Manohar V. Badiger ${ }^{1,2, *}$ \\ 1 Polymer Science and Engineering Division, CSIR-National Chemical Laboratory, Pune 411008, India; \\ n.tiwari@ncl.res.in \\ 2 Academy of Scientific \& Innovative Research, CSIR-NCL Campus, Pune 411008, India; d.sarkar@ncl.res.in \\ 3 Combichem Bioresource Centre, Organic Chemistry Division, CSIR-National Chemical Laboratory, \\ Pune 411008, India; lu.nawale@ncl.res.in \\ * Correspondence: mv.badiger@ncl.res.in; Tel.: +91-20-2590-2187; Fax: +91-20-2590-2612
}

Academic Editor: Gaio Paradossi

Received: 19 January 2017; Accepted: 14 February 2017; Published: 22 February 2017

\begin{abstract}
Mesoporous silica nanoparticles (MSNs) with ordered pore structure have been synthesized and used as carriers for the anticancer drug curcumin. MSNs were functionalized with amine groups and further attached with carboxymethyl cellulose (CMC) using 1-ethyl-3(3-dimethylaminopropyl)-carbodiimide (EDC) coupling chemistry, which increased the hydrophilicity and biocompatibility of MSNs. The functionalized MSNs (MSN-NH $\mathrm{H}_{2}$ and MSN-CMC) were characterized using Scanning Electron Microscopy (SEM), Transmission Electron Microscopy (TEM), Dynamic Light Scattering (DLS), $\mathrm{N}_{2}$ adsorption, X-Ray Diffraction (XRD), Thermo Gravimetric Analysis (TGA) and Fourier Transform Infrared Spectroscopy (FT-IR). The in vitro release of curcumin from the $-\mathrm{NH}_{2}$ and $\mathrm{CMC}$ functionalized MSNs (MSN-cur- $\mathrm{NH}_{2}$ and MSN-cur-CMC) was performed in $0.5 \%$ aqueous solution of sodium lauryl sulphate (SLS). The effect of CMC functionalization of MSNs towards cellular uptake was studied in the human breast cancer cell line MDA-MB-231 and was compared with that of MSN-NH$H_{2}$ and free curcumin (cur). Both $\mathrm{MSN}-\mathrm{NH}_{2}$ and MSN-CMC showed good biocompatibility with the breast cancer cell line. The MTT assay study revealed that curcumin-loaded MSN-cur-CMC showed better uptake as compared to curcumin-loaded MSN-cur- $\mathrm{NH}_{2}$. Free curcumin was used as a control and was shown to have much less internalization as compared to the curcumin-loaded functionalized MSNs due to poor bioavailability. Fluorescence microscopy was used to localize the fluorescent drug curcumin inside the cells. The work demonstrates that CMC-functionalized MSNs can be used as potential carriers for loading and release of hydrophobic drugs that otherwise cannot be used effectively in their free form for cancer therapy.
\end{abstract}

Keywords: curcumin; mesoporous silica nanoparticles; carboxymethyl cellulose; drug delivery

\section{Introduction}

Cancer has become a major concern worldwide as most of the drugs effective in its treatment are hydrophobic in nature and thus have less bioavailability at the required site. Chemotherapy, although clinically accepted for the treatment of cancer, has major side effects linked to the poor specificity of chemotherapeutic, which leads to the death of normal cells along with the cancer cells [1]. Developing controlled-release technology to avoid premature drug release with targeted drug delivery may provide more efficient and less harmful solution compared to conventional chemotherapy. In this context, nanotechnology has emerged as one of the major areas of research for drug delivery towards cancer treatment to overcome the above mentioned problems [2,3]. Various efforts have been 
made in recent years towards the synthesis of nanocarriers for drug delivery and preventing the premature release of drugs before reaching the targeted site. The nanocarriers for drug delivery must possess certain desired properties like biocompatibility, bioavailability, improved circulation half time, chemical stability in in-vivo conditions, inertness towards enzymatic degradation, tissue specificity and controlled drug release. Although various nanocarriers like liposomes, micelles, capsules, dendrimers, carbon nanotubes [4] etc. have been studied, they lack stability in in-vivo conditions and are prone to various enzymatic degradation before reaching the targeted site and results in premature drug release [4]. Recently, inorganic mesoporous silica nanoparticles (MSNs) have attracted increasing attention in bio-medical applications due to their stability in in-vivo conditions, biocompatibility and ease of synthesis [5,6]. The particle and pore size of MSNs can be controlled depending on their applications which make them highly versatile in nature [7-9]. With large surface area, porosity and tuneable pore size, control over the functionalization of surface, ordered mesopores, biocompatibility and stability, MSNs have great advantages over other nanocarriers [9]. The template synthesis is one of the strategy to make mesopores in silica particles which has proven to be a potential route to achieve desired nano architectures [10]. The ordered porous structure in MSNs is important in wide range of applications such as catalysis, adsorption, optics, photochemistry etc. [11]. The control over the dimensions, morphologies, composition and porosity of MSNs has been exploited for synthesizing integrated nanocrystals (INCs) in catalytic applications [12]. MSNs have been successfully explored for various biological applications like drug delivery [13-15], biosensors [16], gene transfection [17,18] etc. Particularly, porous MSNs have become important since their porosity can be successfully utilized for the encapsulation of hydrophobic drugs $[19,20]$ and other bio-molecules. The highly porous structure of MSNs facilitates loading large amounts of drugs so that minimum amount of the carrier is sufficient for drug delivery at the cancer site by enhanced cell permeability (EPR) without any potential side effects. Well-established theory postulates that MSNs tend to accumulate at the cancer site more effectively as compared to normal cells [21,22]. Further, both the outer surface and the pores of MSNs can be selectively functionalized with organic moieties to enhance their biocompatibility and increased circulation time in blood [23]. The functionalization of MSNs can also help in preventing the drug or other bio-molecules present inside the porous structure from enzymatic degradation before reaching the targeted site. Surface functionalization could be achieved by modification of the surface of MSNs with organic moieties that are biocompatible.

A literature review reveals that surface modifications have been carried out using both synthetic molecules like polyethylene glycol [24], folic acid [25], $\beta$-cyclodextrin [26] and polyacrylic acid [27] as well as naturally occurring molecules like amino acids (poly-L-lysine and poly-L-arginine) [17] which are biocompatible with the cell environment. Polysaccharides are another class of naturally occurring polymers with inherent biocompatible and biodegradable properties which can be used to enhance the biocompatibility of MSNs without any potential side effects. For example, chitosan [28,29], hyaluronic acid [30], mannose [31] and alginate [32] are a few of the naturally occurring polysaccharides that have been studied extensively for encapsulation of hydrophobic drug molecules and enhanced permeation of hybrid silica particles inside the tumour cells. Other potential polysaccharides like carboxymethyl cellulose (CMC), carboxymethyl tamarind (CMT) and guar gum (GG) in combination with MSNs are yet to be fully explored for drug delivery applications. Another advantage of the polysaccharides is their degradability by enzymes, by which they can be coated onto drug loaded MSNs and the drug can be released by polysaccharide degradation.

In the present work, we have prepared the functionalized MSNs with a polysaccharide, namely carboxy methyl cellulose (CMC) using an EDC coupling reaction between amine functionalized MSNs (MSN-NH $\mathrm{N}_{2}$ ) and the carboxylic groups of CMC. The pores of MSNs were incubated with the hydrophobic drug curcumin, which has both anticancer and antibacterial activity. It was observed that CMC modified MSNs helped in the enhanced permeation of MSNs inside the tumour cells. An MTT assay of breast cancer cell line, MDA-MB-231 revealed that curcumin loaded and CMC coated MSNs (MSN-cur-CMC) showed better cell inhibition compared to the curcumin loaded MSN-cur- $\mathrm{NH}_{2}$ 
or free curcumin. Apoptosis studies performed on cancer cell line MDA-MB-231 indicated that MSN-cur-CMC shows apoptosis at a lower $\mathrm{GI}_{50}$ concentration compared to that of $\mathrm{MSN}-\mathrm{cur}-\mathrm{NH}_{2}$. Therefore, CMC grafted MSNs show great promise in enhanced internalization of drug molecules inside the cancer cell lines.

\section{Results and Discussion}

\subsection{Functionalization and Characterization of Mesoporous Silica Nanoparticles (MSNs)}

Mesoporous silica nanoparticles (MSNs) were synthesized according to the previous reports [14,33]. The synthetic route of MSNs and its functionalization with amine moieties and carboxymethyl cellulose is given in Scheme 1. Briefly, the synthesis of MSNs was carried out by sol-gel method using cetyltrialkyl amonium bromide (CTAB) as a structure-directing agent and tetraethyl orthosilicate (TEOS) as a silica precursor [17,34]. Functionalization of the outer surface of MSNs with amine moieties was performed using aminopropyl triethoxysilane (APTES). The amino groups were introduced to further functionalize the MSN surface with carboxymethyl cellulose (CMC). The amine groups on MSNs covalently react with the $-\mathrm{COOH}$ groups of $\mathrm{CMC}$ to form amide linkages in the presence of $\mathrm{N}$-hydroxy succinimide (NHS).

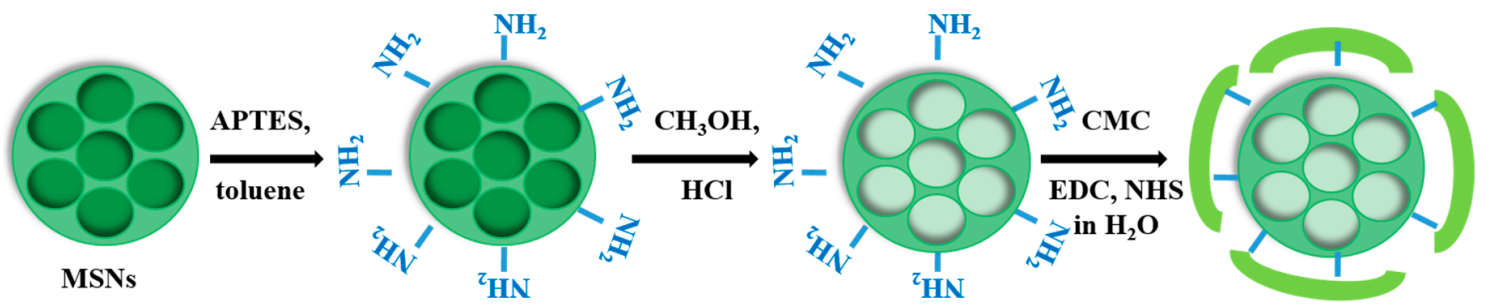

Scheme 1. Synthesis of carboxymethyl cellulose (CMC)-grafted mesoporous silica nanoparticles (MSNs).

TEM images of as-prepared MSNs show uniform discrete spherical nanoparticles with particle sizes in the diameter range of MSN $(120 \pm 20 \mathrm{~nm}), \mathrm{MSN}^{-N_{H}} 2(120 \pm 10 \mathrm{~nm})$ and MSN-CMC $(120 \pm 10 \mathrm{~nm})$. The images also show that MSNs and amine-functionalized MSNs have a porous structure under high magnification (Figure 1a,b). However, this porous structure is covered upon subsequent CMC grafting on to the surface of MSNs (Figure 1c). The observed particle size is in agreement with the sizes obtained from Scanning Electron Microscopy (SEM) (Figure S1 in Supplementary Materials).
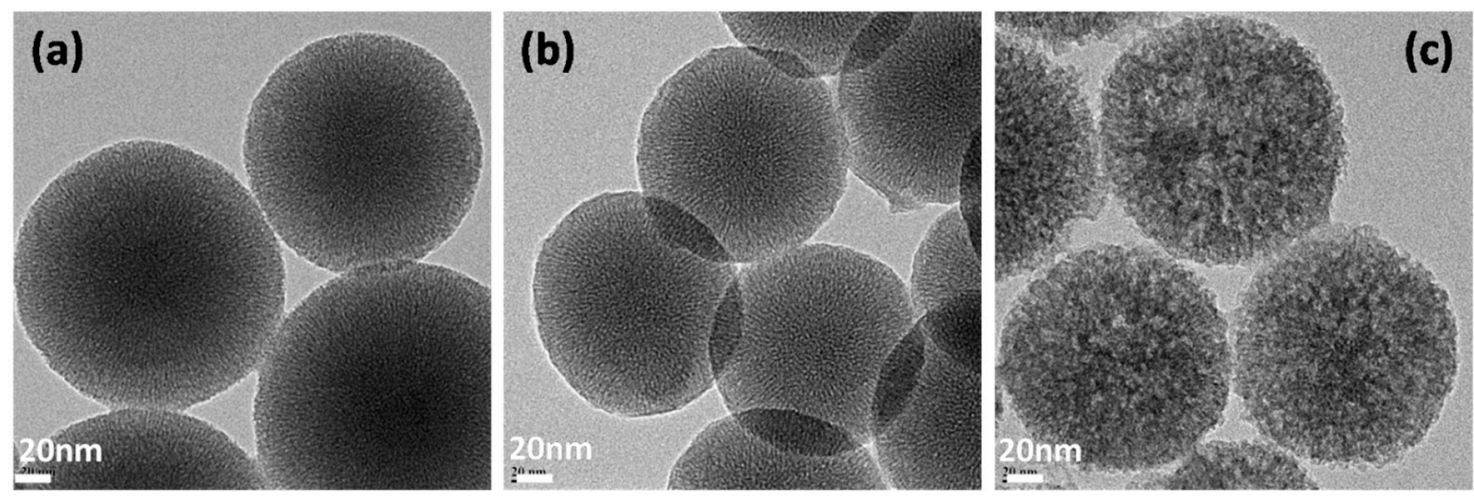

Figure 1. Transmission electron microscopy (TEM) images of (a) MSN; (b) MSN-NH 2 and (c) MSN-CMC.

Further, the particle size distribution and multimodal size distribution of MSNs with and without functionalization was determined using dynamic light scattering (DLS) experiments (Figures 2a and S2). As shown in the Table 1, the diameters of MSNs were found to be larger as compared to diameters 
observed from TEM which could be due to the presence of a hydrated layer in the aqueous environment. The MSN-CMC showed a larger diameter of $\sim 333 \mathrm{~nm}$ since CMC undergoes gelation and swelling in aqueous medium.

(a)

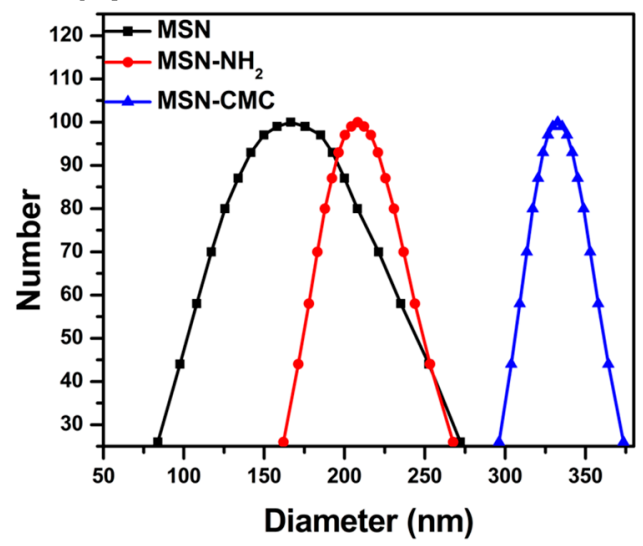

(b)

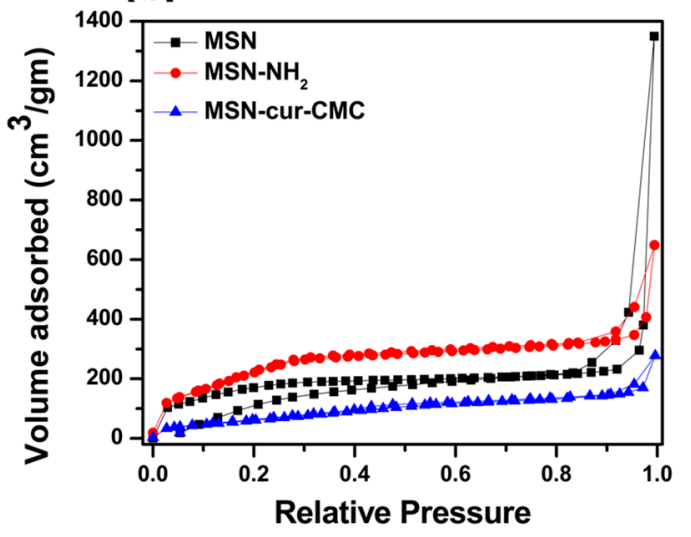

Figure 2. (a) Particle size distribution of MSN and functionalized MSNs obtained by DLS experiments and (b) nitrogen adsorption-desorption isotherms of MSN, MSN-NH $\mathrm{H}_{2}$ and MSN-cur-CMC nanoparticles.

Table 1. Physical properties of various MSNs.

\begin{tabular}{cccc}
\hline Sample Name & Weight Loss (\%) & Hydrodynamic Diameter (nm) & Mean $\zeta$ Potential (mV) in Water \\
\hline MSN & 7.3 & $167 \pm 5$ & $-34.2 \pm 2$ \\
MSN-NH & 17.5 & $210 \pm 7$ & $38.48 \pm 3$ \\
MSN-CMC & 30.7 & $333 \pm 4$ & $-3.07 \pm 2$ \\
\hline
\end{tabular}

MSN, mesoporous silica nanoparticles; CMC, carboxymethyl cellulose.

Aqueous electrophoresis experiments were performed on MSNs to determine their $\zeta$ potential. It was observed that $\zeta$ potential changed from a negative to a positive value upon amine functionalization and later changed to negative value after CMC grafting. This clearly indicated the reaction between the $-\mathrm{NH}_{2}$ groups on MSNs and the $-\mathrm{COOH}$ groups of CMC (Table 1).

Nitrogen adsorption desorption isotherms of MSN, MSN-NH $\mathrm{N}_{2}$ and MSN-cur-CMC showed type IV isotherms, which indicated the mesoporous nature of MSNs as shown in Figure 2b. Barrett, Joyner and Halenda (BJH) method was used for the pore size analysis [35] (see Figure S3). MSNs showed a pore size of $\sim 3 \mathrm{~nm}$, which decreased to $2.7 \mathrm{~nm}$ on amine functionalization. This small decrease in the pore size could be due to the presence of certain amine groups inside the pores. The pore size was further reduced to $2 \mathrm{~nm}$ in the case of MSN-cur-CMC as a result of successful incorporation of curcumin inside the pores of MSNs. The curcumin incorporation also resulted in a decrease of surface area and the pore volume of MSNs as shown in Table 2. The XRD studies of MSNs and MSN-NH 2 showed a well resolved diffraction peak at $2 \theta$ of 2.44 assigned as 100 plane. This confirms the mesoporous structure of MSNs (Figure 3a).

Table 2. Nitrogen adsorption-desorption analysis of MSNs.

\begin{tabular}{cccc}
\hline Sample Name & Surface Area $\left(\mathbf{m}^{2} / \mathbf{g}\right)$ & Pore Diameter $(\mathbf{n m})$ & Pore Volume $\left(\mathbf{c m}^{\mathbf{3}} / \mathbf{g}\right)$ \\
\hline MSN & 939.6 & 3 & 0.738 \\
MSN-NH & 659.1 & 2.6 & 0.642 \\
MSN-cur-CMC & 262.9 & 2 & 0.339 \\
\hline
\end{tabular}


(a)

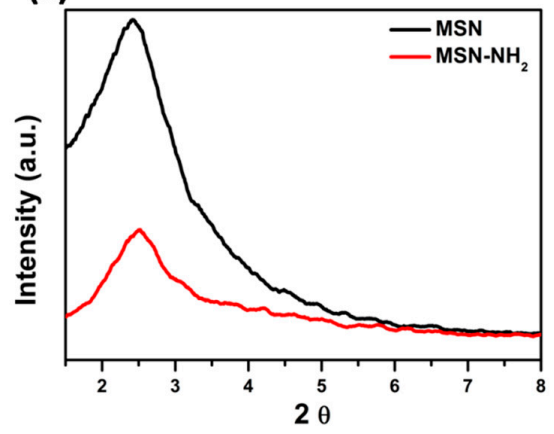

(b)

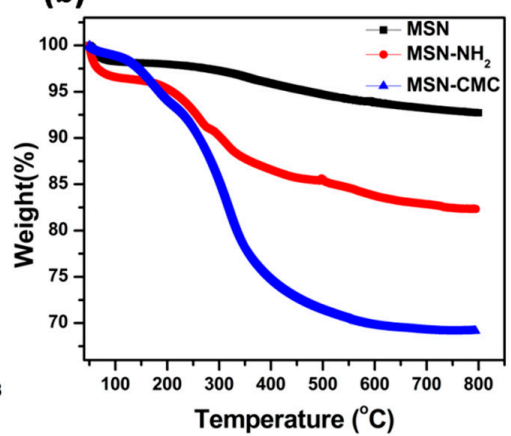

Figure 3. (a) X-Ray Diffraction (XRD) patterns of MSN and MSN-NH $\mathrm{H}_{2}$ and (b) Thermogravimetric Analysis (TGA) curves of MSN, MSN-NH 2 and MSN-CMC.

Further confirmation of the functionalization of MSNs with amine groups and CMC was indicated in the TGA analysis. Figure $3 \mathrm{~b}$ shows the percentage mass loss profiles as a function of temperature for $\mathrm{MSN}-\mathrm{NH}_{2}$ and MSN-CMC. It can be seen that after heating the samples up to $800{ }^{\circ} \mathrm{C}, \mathrm{MSNs}, \mathrm{MSN}-\mathrm{NH}_{2}$ and MSN-CMC show a mass loss of $\sim 7.3 \%, 17.5 \%$ and $30.7 \%$ respectively (Table 1 ). From these results, the percentage grafting of CMC onto MSNs was calculated to be $\sim 13.2 \%$. We also show in Figure 4 , the FT-IR spectra of MSNs, MSN-NH $\mathrm{N}_{2}$ and MSN-CMC. All the samples showed characteristic peaks at 1650 and $800 \mathrm{~cm}^{-1}$ due to $\mathrm{Si}-\mathrm{O}$ stretching and at $480 \mathrm{~cm}^{-1}$ due to $\mathrm{Si}-\mathrm{O}-\mathrm{Si}$ bending. The broad peak at $3400-3500 \mathrm{~cm}^{-1}$ corresponds to $-\mathrm{OH}$ groups in the samples. $\mathrm{MSN}-\mathrm{NH}_{2}$ showed a peak at $2907 \mathrm{~cm}^{-1}$ due to the $\mathrm{C}-\mathrm{H}$ stretching of the poly-amino groups and $1508 \mathrm{~cm}^{-1}$ due to the $-\mathrm{NH}$ bending. However, the peak at $1508 \mathrm{~cm}^{-1}$ disappeared in MSN-CMC due to the functionalization of amine groups with CMC. Further, an additional peak appears in MSN-CMC at $1570 \mathrm{~cm}^{-1}$ due to the amide bending which is absent in MSN-NH${ }_{2}$. This further confirms the successful functionalization of MSNs surface with CMC.
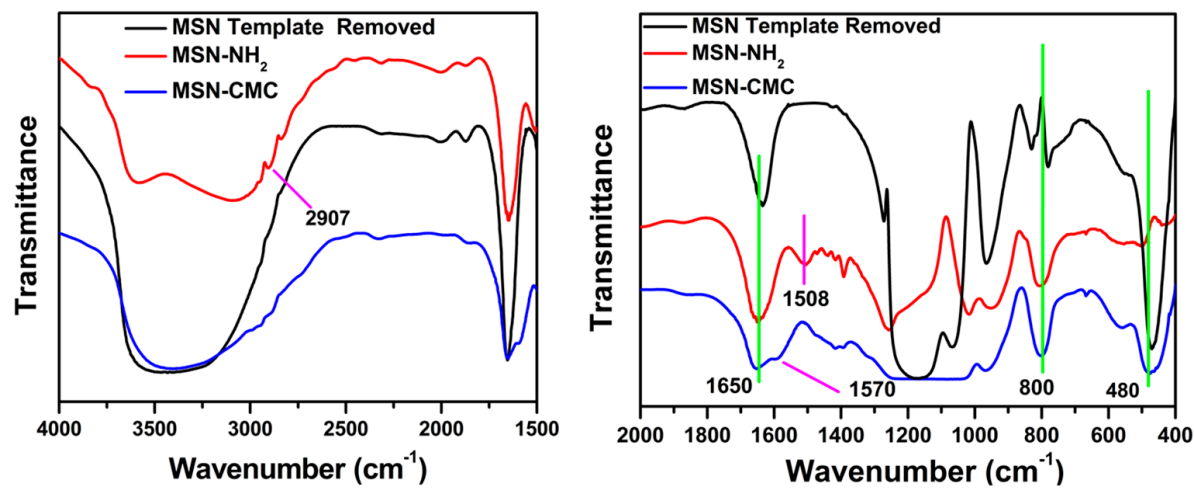

Figure 4. Fourirer Transform Infrared Spectroscopy (FT-IR) Spectra of MSN, MSN-NH 2 and MSN-CMC.

\subsection{Synthesis of Curcumin-Loaded MSNs-Carboxymethyl Cellulose (CMC) Nanoparticles}

Curcumin, an anticancer drug was effectively loaded into the pores of MSNs in order to increase its bioavailability (since it is hydrophobic in nature) and also to prevent its enzymatic degradation before reaching the cancer cells by EPR effect. For curcumin incubation, MSNs surface was first grafted with amine moieties using APTES. Curcumin was then physically incubated into the pores of MSN-NH by stirring MSN-NH${ }_{2}$ in methanol containing curcumin overnight. The curcumin adsorbed on the surface was removed by washing with excess water. The incorporation of curcumin inside the pores of MSNs was confirmed from the reduction in the pore diameter of MSNs from $\mathrm{N}_{2}$ adsorption-desorption isotherms (Table 2). In the next step, $\mathrm{CMC}$ was grafted onto the surface of curcumin-loaded $\mathrm{MSN}-\mathrm{NH}_{2}$ by EDC coupling reaction between $-\mathrm{NH}_{2}$ groups of $\mathrm{MSN}-\mathrm{NH}_{2}$ and $-\mathrm{COOH}$ groups of $\mathrm{CMC}$. The unreacted 
reactants and side products if any were removed by washing with distilled water. The synthetic pathway for the curcumin incorporation in MSN-CMC is shown in Scheme 2.

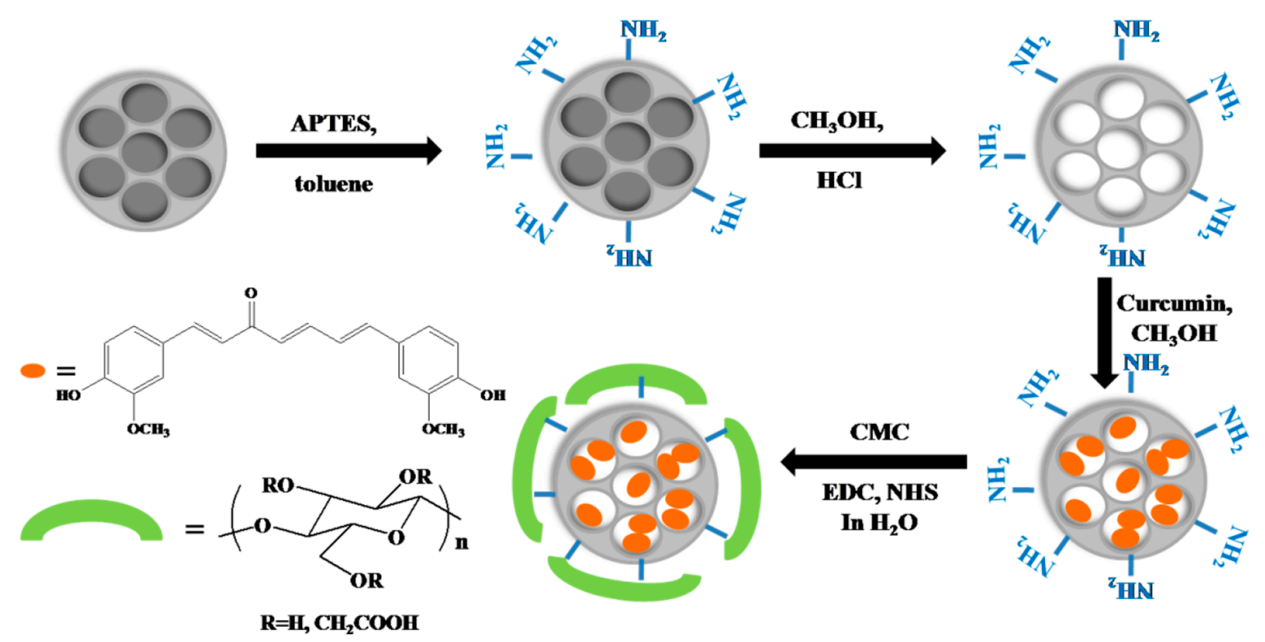

Scheme 2. Synthesis of curcumin-loaded carboxymethyl cellulose grafted MSN.

In order to calculate the amount of curcumin loaded into $\mathrm{MSN}-\mathrm{NH}_{2}$ and $\mathrm{MSN}-\mathrm{CMC}, 1 \mathrm{mg}$ of each material was dispersed in methanol and sonicated for $20 \mathrm{~min}$ using probe sonicator. Nanoparticles were then centrifuged and UV absorbance of the supernatant was carried out at $430 \mathrm{~nm}$. The amount of drug loaded in the MSN nanoparticles is given in Table 3. The drug loading content and the drug entrapment efficiency were calculated using the following equations [24]:

$$
\begin{gathered}
\text { Drug loading content }(\%)=\frac{\text { Weight of curcumin in MSNs }}{\text { Total weight of loaded MSNs }} \times 100 \\
\text { Drug Entrapment Efficiency }(\%)=\frac{\text { Weight of curcumin in MSNs }}{\text { Initial weight of curcumin added }} \times 100
\end{gathered}
$$

Table 3. Curcumin loading in functionalized MSNs.

\begin{tabular}{ccc}
\hline Sample Name & Drug Loading Content (\%) & Drug Entrapment Efficiency (\%) \\
\hline MSN-cur-NH $\mathrm{N}_{2}$ & 10.7 & 71.3 \\
MSN-cur-CMC & 8 & 53.3 \\
\hline
\end{tabular}

\subsection{Release Study of Curcumin from MSN in $0.5 \%$ Sodium Lauryl Sulphate}

The in vitro release of curcumin from MSN-cur- $\mathrm{NH}_{2}$ and MSN-cur-CMC was studied by dispersing curcumin loaded MSNs (with same amount of drug loading) in $10 \mathrm{~mL} 0.5 \%$ sodium lauryl sulphate (SLS) solution at $37^{\circ} \mathrm{C}$ in a water bath with continuous shaking. In our work, SLS (0.5\%) has been used as a drug-releasing medium since curcumin drugs are known to degrade in neutral to basic solutions within a few hours [36]. An aliquot was taken out at fixed time interval and UV absorbance of curcumin at $432 \mathrm{~nm}$ was measured. A total of $45 \%$ curcumin release was observed in MSN-cur- $\mathrm{NH}_{2}$ whereas, only $15 \%$ curcumin could be released from MSN-cur-CMC over a period of $72 \mathrm{~h}$ (Figure 5). A relatively slower release of curcumin from MSN-cur-CMC could be attributed to the presence of $\mathrm{CMC}$ on the surface which creates a barrier for the curcumin molecules to release from the pores of MSN. The slower release of curcumin from MSN-cur-CMC is beneficial since the drug molecules are protected inside the pores of MSNs for a longer period and will be released only after reaching the targeted cancer cells by EPR effect. The drug molecules inside the cells could be easily released by the cleavage of amide linkages (between $\mathrm{CMC}$ and $\mathrm{MSN}-\mathrm{NH}_{2}$ ) by enzymatic action. 


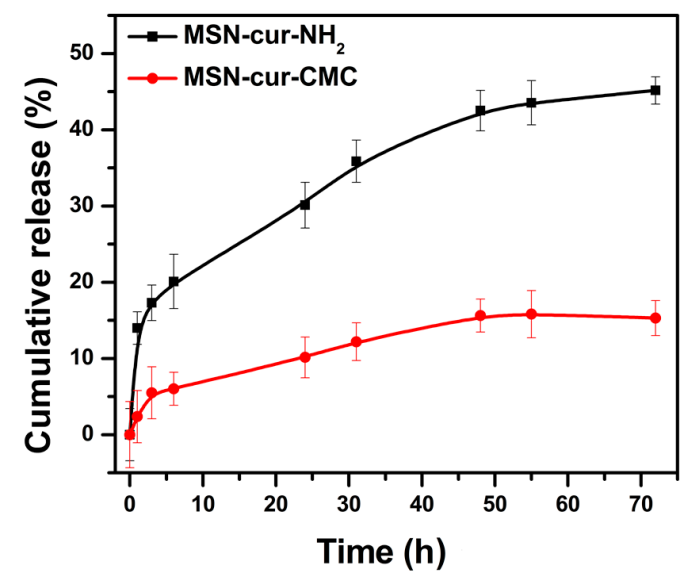

Figure 5. In vitro cumulative release (\%) of curcumin from $\mathrm{MSN}-\mathrm{cur}-\mathrm{NH}_{2}$ and $\mathrm{MSN}$-cur-CMC in $0.5 \%$ sodium lauryl sulphate (SLS).

This is indeed observed in the in vitro studies performed on MDA-MB-231 cancer cell lines.

\subsection{In Vitro Cytotoxicity Assay}

The in vitro cell cytotoxicity of MSN-NH$H_{2}, \mathrm{MSN}-\mathrm{CMC}, \mathrm{MSN}-\mathrm{cur}-\mathrm{NH}_{2}, \mathrm{MSN}-\mathrm{cur}-\mathrm{CMC}$ and free curcumin to MDA-MB-231 cells was investigated using MTT assay. It can be seen from the Figure 6a that $\mathrm{MSN}-\mathrm{NH}_{2}$ and MSN-CMC show almost no toxic effect to the cancer cells up to a concentration of $200 \mu \mathrm{g} / \mathrm{mL}$ after incubation for $24 \mathrm{~h}$. The results indicate that $\mathrm{MSN}^{-\mathrm{NH}_{2}}$ and MSN-CMC are highly biocompatible with the cancer cell line used. Figure $6 \mathrm{~b}$ showed the in vitro cellular toxicity of MSN-cur- $\mathrm{NH}_{2}, \mathrm{MSN}-\mathrm{cur}-\mathrm{CMC}$ and free curcumin in MDA-MB-231 cells at different concentrations. It is observed that free curcumin showed negligible cytotoxicity to the cancer cells. This could be due to curcumin being hydrophobic in nature and has very less solubility in the dispersed medium that might affect least contact with the cancer cells. A comparison of the MTT results of MSN-cur- $\mathrm{NH}_{2}$ and MSN-cur-CMC with the same concentration of curcumin inside the pores indicated that MSN-cur-CMC has higher cell inhibitory effect as compared to that of MSN-cur- $\mathrm{NH}_{2}$. The $\mathrm{GI}_{50}$ of MSN-cur- $\mathrm{NH}_{2}$ and MSN-cur-CMC are found to be 7 and $1.5 \mu \mathrm{g} / \mathrm{mL}$ respectively (Figure $6 \mathrm{~b}$ ). This clearly indicates that CMC functionalization helps with better internalization of curcumin-loaded MSNs, resulting in better inhibition of the cancer cells as compared to MSN-cur- $\mathrm{NH}_{2}$.

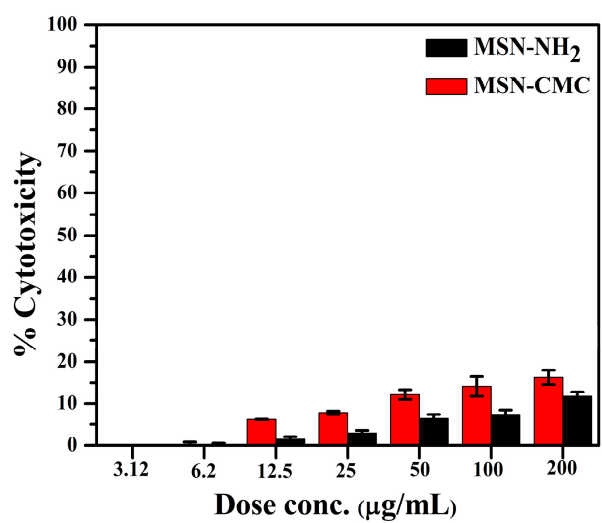

(a)

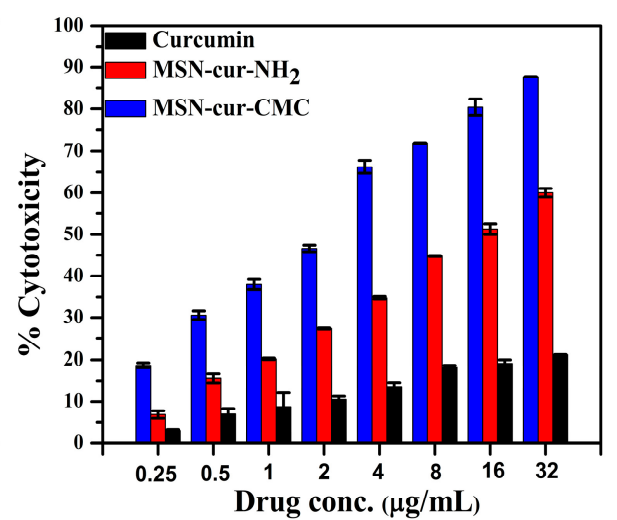

(b)

Figure 6. (a) \% Cytotoxicity of MDAMB 231 cells incubated with $\mathrm{MSN}-\mathrm{NH}_{2}$ and $\mathrm{MSN}-\mathrm{CMC}$ and (b) \% Cytotoxicity of MDA-MB-231 cells incubated with free curcumin, MSN-cur- $\mathrm{NH}_{2}$ and MSN-cur-CMC keeping the amount of curcumin same in all the samples ( $x$ axis represents concentration of free curcumin and curcumin incubated in $\mathrm{MSN}-\mathrm{NH}_{2}$ and MSN-CMC). 


\subsection{Intracellular Uptake of MSN Particles}

For the cellular uptake studies, breast cancer cell line MDA-MB-231 was incubated with free curcumin $(16 \mu \mathrm{g} / \mathrm{mL}), \mathrm{MSN}-\mathrm{cur}-\mathrm{NH}_{2}$ and MSN-cur-CMC $\left(\mathrm{GI}_{50}\right.$ conc. of $\sim 7$ and $1.5 \mu \mathrm{g} / \mathrm{mL}$ respectively). The $\mathrm{GI}_{50}$ concentrations were selected to ensure that the same amount of drug enters the cells (as calculated from MTT assay). Similarly, MSNs without curcumin (MSN-NH ${ }_{2}$ and MSN-CMC) were used as a control at a concentration of $200 \mu \mathrm{g} / \mathrm{mL}$. The fluorescence of curcumin inside the cells was captured after $1 \mathrm{~h}$ of incubation of the MSNs (with and without curcumin) and free curcumin. It was observed that free curcumin does not show fluorescence after $1 \mathrm{~h}$, whereas $\mathrm{MSN}$-cur- $\mathrm{NH}_{2}$ and MSN-cur-CMC showed fluorescence of curcumin molecules. It was also evident from the images that MSN-cur-CMC showed much better fluorescence due to curcumin as compared to that of MSN-cur-NH ${ }_{2}$ (Figure 7). This confirms that CMC-grafted MSNs help with better internalization of curcumin inside the cells as compared to $\mathrm{MSN}-\mathrm{NH}_{2}$ since the $\mathrm{GI}_{50}$ of MSN-cur-CMC is much lower compared to that of MSN-cur- $\mathrm{NH}_{2}$. The control experiments with $\mathrm{MSN}-\mathrm{NH}_{2}$ and MSN-CMC do not show any fluorescence, as expected (Figure S4). The results indicate that the CMC-coated MSNs are internalized.

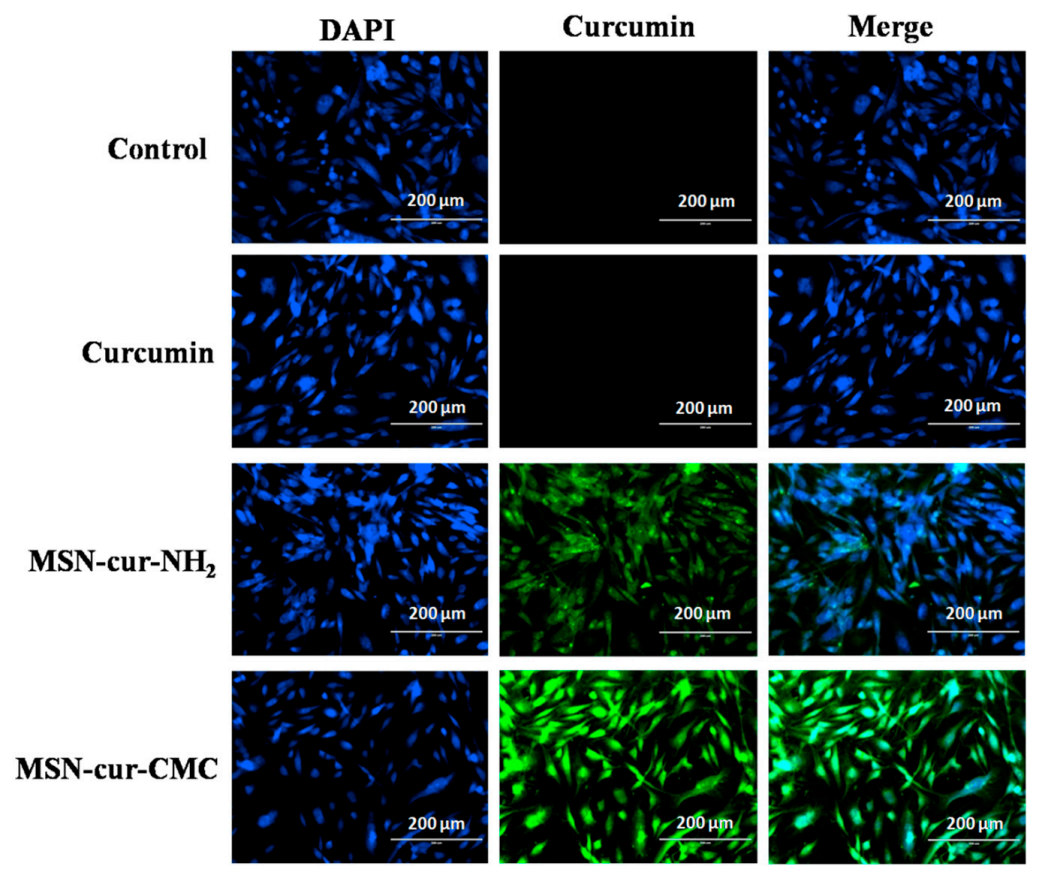

Figure 7. Intracellular uptake of $-\mathrm{NH}_{2}$ and $-\mathrm{CMC}$ functionalized MSNs using fluorescence microscopy. Images of MDA-MB-231 incubated with $16 \mu \mathrm{g} / \mathrm{mL}$ of free curcumin, MSN-cur-NH $\mathrm{NH}_{2}\left(\mathrm{GI}_{50}=7 \mu \mathrm{g} / \mathrm{mL}\right)$ and MSN-cur-CMC $\left(\mathrm{GI}_{50}=1.5 \mu \mathrm{g} / \mathrm{mL}\right)$. Control refers to the non-treated MDA-MB-231 cells. Blue fluorescence is due to nucleus staining of cells with 4',6-Diamidino-2-Phenylindole Dihydrochloride (DAPI) and green is due to fluorescence of curcumin release inside the cells effectively in MDA-MB-231 cancer cells, which is also in agreement with the MTT assay where the comparable \% cytotoxicity in the cells is absent.

\subsection{Apoptosis by Fluorescein Isothiocyanate (FITC)-Labeled Annexin V (Annexin V-FITC)/Propidium Iodide (PI) Staining}

In order to find out whether the curcumin-loaded MSNs mediate decreases in cell growth due to apoptosis, we investigated apoptosis in MDA-MB-231 cells using annexin fluorescein isothiocyanate (FITC)-labeled annexin V (annexin V-FITC)/propidium iodide (PI) and 4',6-Diamidino-2-Phenylindole Dihydrochloride (DAPI) as the staining agents. We observed that treatment of cells with free curcumin $(16 \mu \mathrm{g} / \mathrm{mL})$ and $\mathrm{GI}_{50}$ concentrations of MSN-cur-NH $2(7 \mu \mathrm{g} / \mathrm{mL})$ and MSN-cur-CMC $(1.5 \mu \mathrm{g} / \mathrm{mL})$ 
resulted in increase in the apoptotic cells in $48 \mathrm{~h}$ (Figure 8). The MSNs without curcumin, taken as a control, did not show any green fluorescence due to annexin V-FITC/PI, indicating no apoptosis in the cells, and are thus biocompatible (Figure S5). The calculated apoptotic ratios in $48 \mathrm{~h}$ for control, curcumin, MSN-cur-NH $\mathrm{N}_{2}$ and MSN-cur-CMC were found to be $2.5 \%, 9.7 \%, 49 \%$ and $69 \%$ respectively (Figure 9). The high apoptotic value of MSN-cur-CMC compared to free curcumin and MSN-cur- $\mathrm{NH}_{2}$ further confirmed that CMC coating on the MSN surface helps with better uptake of MSNs inside the cells and hence more curcumin molecules are released effectively at the targeted site. We also observed that PI positive cells were not observed in the experiment suggesting the absence of necrosis. In order to prove that the green fluorescence observed in the cells after treatment with MSN-cur- $\mathrm{NH}_{2}$ and MSN-cur-CMC is due to staining of the cells with annexin V-FITC and not due to fluorescence due to curcumin molecules, we performed the imaging of the cells without annexin V-FITC after $48 \mathrm{~h}$ (Figure S6). We observed that in absence of annexin V-FITC, green fluorescence was absent in the cells as the fluorescence due to curcumin do not last for longer time due to quenching (i.e., degradation of curcumin) [36]. This experiment proves that MSN-cur-CMC induces cell death in the MDA-MB-231 cell line via apoptotic pathway.

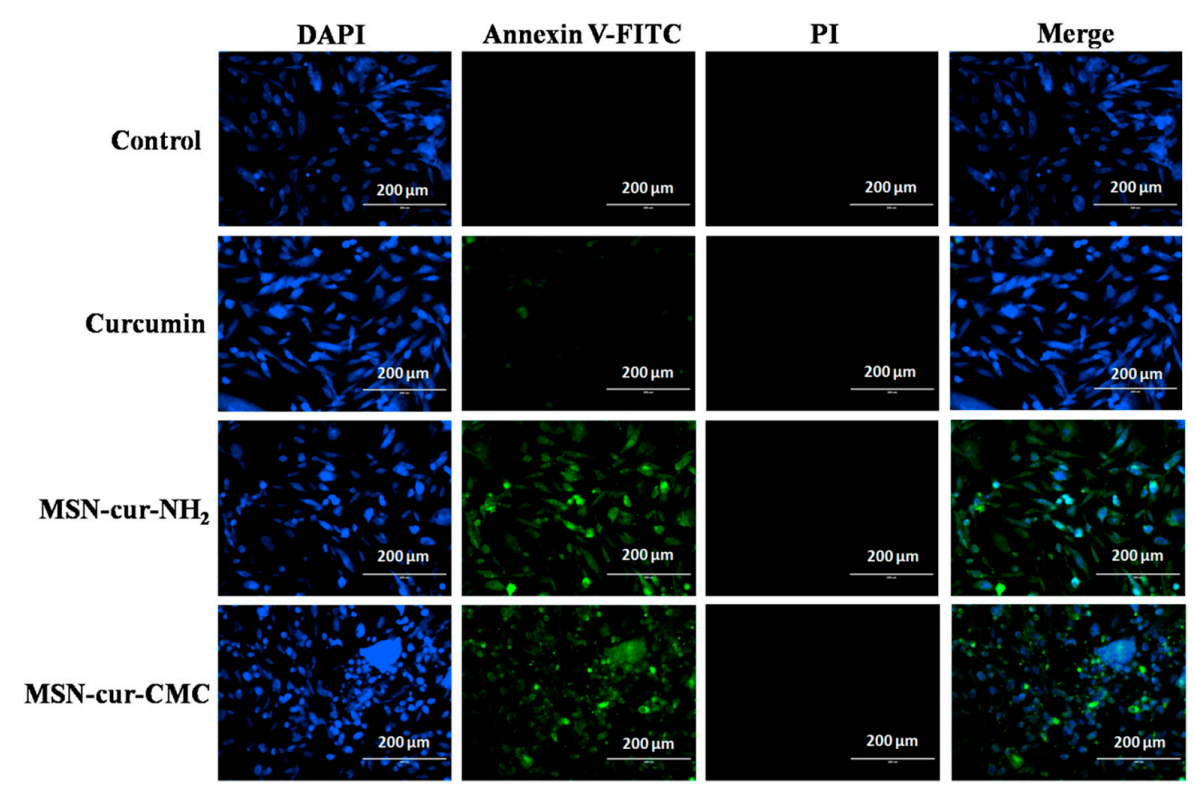

Figure 8. Apoptosis of MDA-MB-231 cells using fluorescence microscopy. Images of MDA-MB-231 incubated with $16 \mu \mathrm{g} / \mathrm{mL}$ of free curcumin, MSN-cur-NH2 $\left(\mathrm{GI}_{50}=7 \mu \mathrm{g} / \mathrm{mL}\right)$ and MSN-cur-CMC $\left(\mathrm{GI}_{50}=1.5 \mu \mathrm{g} / \mathrm{mL}\right)$. Control refers to the non-treated MDA-MB-231 cells. Blue fluorescence is due to nucleus staining of cells with DAPI and green fluorescence is due to staining of cells by annexin V-FITC.

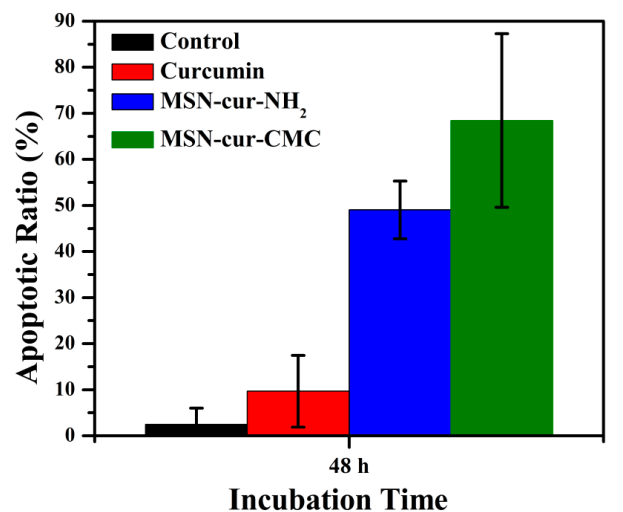

Figure 9. Apoptotic ratios of free curcumin, $\mathrm{MSN}-\mathrm{cur}-\mathrm{NH}_{2}$ and $\mathrm{MSN}-\mathrm{cur}-\mathrm{CMC}$ in $48 \mathrm{~h}$. 


\section{Conclusions}

In conclusion, we have successfully synthesized MSNs with particle sizes in the range of 120-130 nm and pore size of $2-3 \mathrm{~nm}$ as confirmed by TEM, SEM and $\mathrm{N}_{2}$ adsorption-desorption studies. The grafting of MSNs with $-\mathrm{NH}_{2}$ and $\mathrm{CMC}$ moieties on the surface was confirmed by a decrease in the surface area by $\mathrm{N}_{2}$ - adsorption data and weight loss by TGA data. Also, the zeta potential showed a change in the sign of the charge from positive to negative upon grafting with $-\mathrm{NH}_{2}$ and $\mathrm{CMC}$, which also confirmed the functionalization. The drug release profile in $0.5 \%$ SLS solution showed only a $15 \%$ release of curcumin molecules from MSN-cur-CMC as compared to $45 \%$ from MSN-cur-NH $\mathrm{N}_{2}$ over a period of $72 \mathrm{~h}$. The release profile indicated that $\mathrm{CMC}$ helped in preventing curcumin molecules from experiencing premature release over a longer period of time. An MTT assay showed there were negligible toxic effects of MSN-NH$H_{2}$ and MSN-CMC on breast cancer cell line MDA-MB-231 up to a concentration of $200 \mu \mathrm{g} / \mathrm{mL}$, thus indicating biocompatibility of the functionalized MSNs. MSN-cur-CMC showed enhanced cellular uptake and percent cytotoxicity as compared to MSN-cur-NH2 as observed in the MTT assay (from $\mathrm{GI}_{50}$ values) on MDA-MB-231 breast cancer cell line. Apoptosis studies performed over a period of $48 \mathrm{~h}$ showed that MSN-cur-CMC induces cell death in the MDA-MB-231 cell line via apoptotic pathway. All the above-mentioned observations indicate that CMC grafting on the surface of MSNs enhanced the cellular uptake and cytotoxicity of the cells at remarkably lower concentrations of the curcumin drug. These studies demonstrate that MSN-CMC nanogels could be used as model systems for enhanced cellular uptake and drug delivery applications.

\section{Materials and Synthesis}

\subsection{Materials}

Tetraethylorthosilicate (TEOS) (99\%), (3-aminopropyl) triethoxysilane (APTES), hexadecyltrime thylammonium bromide (CTAB) (99\%), 1-ethyl-3-(3-dimethylaminopropyl)-carbodiimide hydrochloride (EDC. $\mathrm{HCl}$ ), N-hydroxy succinimide (NHS), sodium lauryl sulphate (SLS), Potassium Bromide (KBr), Polytetrafluoroethylene (PTFE) filters and carboxymethyl cellulose (CMC) were obtained from Sigma Aldrich, St. Louis, MO, USA. Curcumin was a gift sample from Arjuna Natural Extracts, Kerala, India. Dulbecco's modified Eagle's medium (DMEM) high glucose, fetal bovine serum (FBS), L-15 medium, Trypsin (0.25\% EDTA), annexin-V FITC, 4',6-Diamidino-2-Phenylindole Dihydrochloride (DAPI), propidium iodide (PI), RNAse A, 4-(2-hydroxyethyl)-1-piperazineethanesulfonic acid (HEPES) buffer, paraformaldehyde (4.7\%) and 3-(4,5-dimethylthiazol-2-yl)-2,5-diphenyltetrazolium bromide (MTT) were procured from Invitrogen, Bangalore, India. All chemicals were used as received. The required cell lines for this work (MDA-MB-231) were purchased from National Center for Cell Science (NCCS), Pune, India.

\subsection{Synthesis}

\subsubsection{Synthesis of Mesoporous Silica Nanoparticles}

One gram of Cetyltrimethylammonium bromide (CTAB) was dissolved in $480 \mathrm{~mL}$ of deionized water using an overhead stirrer at room temperature followed by the addition of $2 \mathrm{M} \mathrm{NaOH}$ solution (3.5 mL). The solution was allowed to stir for $30 \mathrm{~min}$ at $80^{\circ} \mathrm{C} .5 \mathrm{~mL}$ of tetraethyl orthosilicate (TEOS) was added drop wise to the above mixture. The mixture was stirred at $6000 \mathrm{rpm}$ for another $2 \mathrm{~h}$ at $80^{\circ} \mathrm{C}$. The resultant white precipitate was collected by vacuum filtration and washed with copious amount of water. The precipitate was dried in vacuum oven overnight to obtain mesoporous silica in powder form. The removal of the surfactant was carried out by dispersing $1 \mathrm{~g}$ of MSN in $100 \mathrm{~mL}$ methanol and $1 \mathrm{~mL}$ of hydrochloric acid. The solution was refluxed for $6 \mathrm{~h}$. The CTAB removed MSNs were obtained by vacuum filtration and dried in oven overnight. 


\subsubsection{Outer Surface Functionalization of MSNs with Amino Groups}

For the outer surface functionalization of MSNs, $1 \mathrm{~g}$ of MSNs (containing CTAB) were dispersed in $100 \mathrm{~mL}$ anhydrous toluene followed by addition of $200 \mu \mathrm{L}$ of 3-aminopropyltriethoxysilane (APTES) in the presence of a catalytic amount of $\mathrm{Et}_{3} \mathrm{~N}$. The reaction mixture was refluxed for $18 \mathrm{~h}$ under argon atmosphere. The material was then vacuum filtered, washed with toluene and finally with ethanol. The template (CTAB) was removed by refluxing the material with acidic methanol solution for $6 \mathrm{~h}$. The amine grafted and template removed MSNs were finally washed with methanol and vacuum dried. The obtained material was denoted as $\mathrm{MSN}-\mathrm{NH}_{2}$.

\subsubsection{Curcumin Loading in $\mathrm{MSN}-\mathrm{NH}_{2}$}

To load curcumin into MSN-NH $2,200 \mathrm{mg}$ of MSN-NH2 was dispersed in $20 \mathrm{~mL}$ of methanol using probe sonicator. To this dispersion, $30 \mathrm{mg}$ of curcumin dissolved in $10 \mathrm{~mL}$ methanol was added. The dispersion was stirred overnight at $25^{\circ} \mathrm{C}$. Methanol was then evaporated under vacuum at $50{ }^{\circ} \mathrm{C}$. The curcumin loaded MSNs were then dispersed in water using a sonicator. The MSNs were centrifuged at $12,000 \mathrm{rpm}$ for $10 \mathrm{~min}$ and washed several times with water in order to remove any curcumin adsorbed on the surface. The particles were then dried under vacuum overnight to obtain curcumin loaded MSNs. The obtained material was denoted as MSN-cur- $\mathrm{NH}_{2}$.

\subsubsection{Functionalization of $\mathrm{MSN}-\mathrm{NH}_{2}$ and $\mathrm{MSN}-$ cur- $\mathrm{NH}_{2}$ by Carboxymethyl Cellulose}

One hundred milligram of MSN-NH $\mathrm{N}_{2}$ and MSN-cur- $\mathrm{NH}_{2}$ were dispersed in $100 \mathrm{~mL}$ deionized water using sonication. To this, a premixed solution of NHS $(0.4 \mathrm{~g})$, EDC (0.2 g) and carboxymethyl cellulose $(150 \mathrm{mg})$ in $20 \mathrm{~mL}$ deionized water was added [37]. The $\mathrm{pH}$ of the solution was then adjusted to 9 with an addition of triethylamine. The solution was stirred overnight at $40{ }^{\circ} \mathrm{C}$. The product was centrifuged at 12,000 rpm for $10 \mathrm{~min}$ followed by 3 times washing with deionized water to remove any unreacted reactants. The precipitate was then dried under vacuum overnight to obtain curcumin loaded CMC grafted MSN particles. The material was denoted as MSN-cur-CMC (with curcumin) and MSN-CMC (without curcumin).

\subsubsection{In Vitro Curcumin Release Studies}

The in vitro release of curcumin from MSN-cur- $\mathrm{NH}_{2}$ and MSN-cur-CMC were performed in $0.5 \%$ SLS solution. Both MSN-cur- $\mathrm{NH}_{2}$ and MSN-cur-CMC equivalent to $1 \mathrm{mg}$ of curcumin were suspended in $10 \mathrm{~mL} 0.5 \%$ SLS solution and kept at shaking water bath preset at $37^{\circ} \mathrm{C}$. One milliliter of the supernatant was collected at predetermined time intervals and immediately replaced with equal amount of dissolution medium in order to maintain the sink conditions. The supernatant collected was centrifuged to remove any solid particles and appropriately diluted before taking the absorbance at $432 \mathrm{~nm}$ using a UltraViolet-Visible (UV-Vis) spectrophotometer (Shimadzu, Kyoto, Japan). The release profiles of curcumin from MSN-cur-NH$H_{2}$ and MSN-cur-CMC were evaluated at $37^{\circ} \mathrm{C}$ for $72 \mathrm{~h}$.

\subsubsection{In Vitro Cytotoxicity Assay}

The sensitivity of MDA-MB-231 cells to the curcumin loaded MSNs was determined by MTT dye uptake as described previously. Briefly, $1 \times 10^{5}$ cells $/ \mathrm{mL}$ was seeded in a flat bottomed 96 -well plate. Next day, the cells were treated with increasing concentrations of blank $(3.125-200 \mu \mathrm{g} / \mathrm{mL}$ final concentrations) and curcumin loaded MSNs $(0.12-16 \mu \mathrm{g} / \mathrm{mL}$ final drug concentrations) in sterilized MilliQ water and incubated at $37{ }^{\circ} \mathrm{C}$ with $5 \% \mathrm{CO}_{2}$ for $24 \mathrm{~h}$. An untreated group was kept as a negative control and cells treated with free curcumin $(0.12-16 \mu \mathrm{g} / \mathrm{mL})$ were used as positive control. Wells containing culture medium and MTT but no cells acted as blank. After incubation, the MTT solution ( $5 \mathrm{mg} / \mathrm{mL}$ solution in PBS) was added to each well and the cells were incubated for another $3.5 \mathrm{~h}$ at $37{ }^{\circ} \mathrm{C}$ in $5 \% \mathrm{CO}_{2}$ incubator. The formazan crystals formed were dissolved by addition of $200 \mu \mathrm{L}$ of $0.04 \mathrm{~N}$ acidified isopropanol. After $15 \mathrm{~min}$, the amount of colored formazan 
derivative formed was determined by measuring optical density (OD) using the microplate reader at $570 \mathrm{~nm}$. All experiments were conducted in triplicates and the results were presented as average with \pm standard deviation. The percentage inhibition was calculated as:

$$
\% \text { Inhibition }=100-\left[\frac{(\mathrm{OD} \text { of control well }- \text { OD of treated well })}{(\text { OD of control well }- \text { OD of blank })} \times 100\right]
$$

\subsubsection{Intracellular Uptake of MSNs}

The fluorescence of curcumin was used to determine the uptake of curcumin loaded MSNs inside the breast cancer cell line MDA-MB-231. Briefly, $1 \times 10^{5}$ cells $/ \mathrm{mL}$ was seeded in a glass bottomed black 96-well plate. Next day, cells were treated with $\mathrm{MSN}^{-N_{2}} \mathrm{H}_{2}$ and MSN-CMC $(200 \mu \mathrm{g} / \mathrm{mL})$, curcumin $(16 \mu \mathrm{g} / \mathrm{mL})$ and MSN-cur- $\mathrm{NH}_{2}$ and MSN-cur-CMC $\left(\mathrm{GI}_{50}=7\right.$ and $1.5 \mu \mathrm{g} / \mathrm{mL}$ final drug concentrations respectively) in sterilized MilliQ water (Merck, Darmstadt, Germany) and incubated at $37^{\circ} \mathrm{C}$ with $5 \% \mathrm{CO}_{2}$ for $1 \mathrm{~h}$. Following incubation, the cells were washed with PBS and stained with DAPI. An alteration in released curcumin level was detected using Laser Scanning Confocal Microscope (LSCM) (Thermo Fischer, Waltham, MA, USA) by measuring the green fluorescence (excitation $490 \mathrm{~nm}$, emission $530 \mathrm{~nm}$ ).

\subsubsection{Apoptosis by Annexin V-FITC/PI Staining}

Apoptosis was evaluated by the binding of annexin V-FITC to phosphatidylserine that gets externalized to the outer leaflet of the plasma membrane, followed by high content screening. After $48 \mathrm{~h}$ of incubation of the cells with MSN-NH${ }_{2}$ and MSN-CMC $(200 \mu \mathrm{g} / \mathrm{mL})$, curcumin $(16 \mu \mathrm{g} / \mathrm{mL})$ and MSN-cur- $\mathrm{NH}_{2}$ and MSN-cur-CMC ( $\left(\mathrm{GI}_{50}=7\right.$ and $1.5 \mu \mathrm{g} / \mathrm{mL}$ final drug concentrations respectively), the cells were harvested and subsequently treated with annexin V-binding buffer comprising annexin V-FITC $(3 \mu \mathrm{g} / \mathrm{mL})$, DAPI $(1 \mu \mathrm{M})$ and propidium iodide $(10 \mu \mathrm{g} / \mathrm{mL})$ [38]. The number of cells undergoing apoptosis were examined using LSCM (20× magnification, Olympus FV1000) (Olympus, Melville, NY, USA and Thermo Scientific ${ }^{\mathrm{TM}}$ HCS studio ${ }^{\mathrm{TM}} 2.0$ software (Thermo Fischer Scientific, Waltham, MA, USA) was used for three-dimensional multichannel-image processing. The apoptotic ratio was calculated as:

$$
\% \text { Apoptotic ratio }=\frac{(\text { Number of cells positive for annexin V }- \text { FITC })}{(\text { Number of cells positive for DAPI })} \times 100
$$

\section{Characterizations}

\subsection{Fourier Transform Infrared Spectroscopy (FT-IR)}

FT-IR spectra were recorded on Perkin Elmer FT-IR spectrum GX instrument (Perkin Elmer, Waltham, MA, USA) using KBr pellets. Pellets were prepared by mixing $3 \mathrm{mg}$ of sample with $97 \mathrm{mg}$ of $\mathrm{KBr}$.

\subsection{Thermo Gravimetric Analysis}

Thermo gravimetric analysis (TGA) of the MSNs were carried out using a TA Instrument SDT Q600 analyzer (TA Instruments, New Castle, DE, USA) between 50 and $800{ }^{\circ} \mathrm{C}$ in air (flow $50 \mathrm{~mL} \cdot \mathrm{min}^{-1}$ ) at an heating rate of $10{ }^{\circ} \mathrm{C} \cdot \mathrm{min}^{-1}$. All samples were dried under vacuum at $60^{\circ} \mathrm{C}$ overnight prior to TGA runs. The graft density of the grafted moiety on the silica surface was determined by thermo gravimetric analysis (TGA) as described before.

\subsection{Transmission Electron Microscopy (TEM)}

HR-TEM images were taken on a FEI Technai F30 operating (FEI, Hillsboro, OR, USA) at $300 \mathrm{kV}$ with Field Emission Gun (FEG). The samples were prepared by dispersing a $0.1 \mathrm{mg} / \mathrm{mL}$ of MSNs in 
methanol by sonication, dropping the resulting suspension on a copper grid of 400 meshes for $30 \mathrm{~s}$ and allowing it to dry in air.

\subsection{Scanning Electron Microscopy (SEM)}

Scanning electron Microscopy (SEM) was used to investigate the morphology of the MSNs using Quanta 200 3D (FEI) dual beam having electron source of tungsten (W) filament with emission at resolution of $20 \mathrm{kV}$ in high vacuum. All the samples were sputter-coated with a thin layer of gold.

\subsection{Nitrogen Adsorption/Desorption}

Nitrogen adsorption/desorption studies at $-196{ }^{\circ} \mathrm{C}$ were carried out using Quadrasorb SI instrument (Quantachrome Instruments, Burlington, ON, Canada). The samples were degassed overnight under vacuum using FloVac Degasser (Quantachrome Instruments, Burlington, ON, Canada) at $100{ }^{\circ} \mathrm{C}$ before nitrogen adsorption measurements. Multi-point Brunauer-Emmett-Teller (BET) surface area was obtained from the nitrogen adsorption isotherm in the relative pressure range from 0.1 to 0.3 . Pore sizes were calculated using the Barrett, Joyner and Halenda (BJH) method from adsorption branch of the isotherm in the relative pressure range from 0.3 to 0.99 units and total pore volume was calculated at $P / P_{\mathrm{o}}$ of 0.99 .

\section{6. $\zeta$ Potential and Size Determination}

The hydrodynamic diameters of dilute aqueous solutions of the MSNs, MSN-NH 2 and MSN-CMC were determined by dynamic light scattering (DLS) (Brookhaven Instruments, Holtsville, NY, USA) equipped with a He-Ne laser operating at $632 \mathrm{~nm}$. The particle size was calculated using 90 Plus particle Sizing Software Ver. 3.94 (Brookhaven Instruments). Sample solutions $1 \mathrm{mg} / \mathrm{mL}$ were made in water and were filtered using a $0.8 \mu \mathrm{m}$ Polytetrafluoroethylene (PTFE) filter.

Aqueous electrophoretic data for the above mentioned MSNs were obtained using Brookhaven Instruments. For each sample three measurements were taken and the average value is reported. $\zeta$ potentials were calculated using PALS $\zeta$ Potential Analyzer Software Ver. 3.54 (Brookhaven Instruments).

Supplementary Materials: The following are available online at www.mdpi.com/2310-2861/3/1/8/s1, Figure S1: SEM image of as synthesized MSNs; Figure S2: DLS of MSN, MSN-NH $\mathrm{N}_{2}$ and MSN-CMC; Figure S3: Pore diameter of MSN, MSN-NH 2 and MSN-cur-CMC using BJH method from $\mathrm{N}_{2}$-adsortion desorption studies; Figure S4: Intracellular uptake of MSN-NH${ }_{2}$ and MSN-CMC using fluorescence microscopy. Images are at a magnification of $200 \mu \mathrm{m}$ of MDA-MB-231 incubated with a concentration of $200 \mu \mathrm{g} / \mathrm{mL}$. Blue fluorescence is due to nuclei staining of cell with DAPI; Figure S5: Apoptosis of MDA-MB-231 cells using fluorescence microscopy. Images are at a magnification of $200 \mu \mathrm{m}$ of MDA-MB-231 incubated with $200 \mu \mathrm{g} / \mathrm{mL}$ of MSN-NH${ }_{2}$ and MSN-CMC. Blue fluorescence is due to nuclei staining of cell with DAPI and Figure S6: Intracellular uptake of $-\mathrm{NH}_{2}$ and -CMC functionalized MSNs using fluorescence microscopy after $48 \mathrm{~h}$. Images of MDA-MB-231 incubated with $16 \mu \mathrm{g} / \mathrm{mL}$ of free curcumin, MSN-cur-NH${ }_{2}\left(\mathrm{GI}_{50}=7 \mu \mathrm{g} / \mathrm{mL}\right)$ and $\mathrm{MSN}$-cur-CMC $\left(\mathrm{GI}_{50}=1.5 \mu \mathrm{g} / \mathrm{mL}\right)$. Control refers to the non treated MDA-MB-231 cells. Blue fluorescence is due to nuclei staining of cell with DAPI and green due to fluorescence of curcumin release inside the cells.

Acknowledgments: Neha Tiwari is grateful to Council of Scientific \& Industrial Research (CSIR), New Delhi for Senior Research Fellowship (SRF). Manohar V. Badiger is grateful to the research grant received from CSIR, New Delhi (CSC0134).

Author Contributions: Neha Tiwari and Manohar V. Badiger conceived and designed the experiments; Neha Tiwari performed the experiments; Neha Tiwari and Manohar V. Badiger analyzed the data; Laxman Nawale and Dhiman Sarkar contributed reagents and analysis tools; Neha Tiwari wrote the paper.

Conflicts of Interest: The authors declare no conflict of interest.

\section{References}

1. Yang, K.N.; Zhang, C.Q.; Wang, W.; Wang, P.C.; Zhou, J.P.; Liang, X.J. pH-responsive mesoporous silica nanoparticles employed in controlled drug delivery systems for cancer treatment. Cancer Biol. Med. 2014, 11, 34-43. [PubMed] 
2. De, M.; Ghosh, P.S.; Rotello, V.M. Applications of nanoparticles in biology. Adv. Mater. 2008, 20, 4225-4241. [CrossRef]

3. Faraji, A.H.; Wipf, P. Nanoparticles in cellular drug delivery. Bioorg. Med. Chem. 2009, 17, $2950-2962$. [CrossRef] [PubMed]

4. Kwon, S.; Singh, R.K.; Perez, R.A.; Abou Neel, E.A.; Kim, H.W.; Chrzanowski, W. Silica-based mesoporous nanoparticles for controlled drug delivery. J. Tissue Eng. 2013, 4, 2041731413503357. [CrossRef] [PubMed]

5. Wang, S. Ordered mesoporous materials for drug delivery. Microporous Mesoporous Mater. 2009, 117, 1-9. [CrossRef]

6. Vallet-Regí, M.; Ruiz-González, L.; Izquierdo-Barba, I.; González-Calbet, J.M. Revisiting silica based ordered mesoporous materials: Medical applications. J. Mater. Chem. 2006, 16, 26-31. [CrossRef]

7. Bouchoucha, M.; Côté, M.-F.; C.-Gaudreault, R.; Fortin, M.-A.; Kleitz, F. Size-controlled functionalized mesoporous silica nanoparticles for tunable drug release and enhanced anti-tumoral activity. Chem. Mater. 2016, 28, 4243-4258. [CrossRef]

8. Harrison, W. Synthesis and characterization of ordered mesoporous silica nanoparticles with tunable physical properties by varying molar composition of reagents. Afr. J. Pharm. Pharmacol. 2011, 5, 2402-2410. [CrossRef]

9. Morell, J.; Güngerich, M.; Wolter, G.; Jiao, J.; Hunger, M.; Klar, P.J.; Fröba, M. Synthesis and characterization of highly ordered bifunctional aromatic periodic mesoporous organosilicas with different pore sizes. J. Mater. Chem. 2006, 16, 2809-2818. [CrossRef]

10. Malgras, V.; Ji, Q.; Kamachi, Y.; Mori, T.; Shieh, F.-K.; Wu, K.C.-W.; Ariga, K.; Yamauchi, Y. Templated synthesis for nanoarchitectured porous materials. Bull. Chem. Soc. Jpn. 2015, 88, 1171-1200. [CrossRef]

11. Yamamoto, E.; Kuroda, K. Colloidal mesoporous silica nanoparticles. Bull. Chem. Soc. Jpn. 2016, 89, 501-539. [CrossRef]

12. Zhan, G.; Zeng, H.C. Integrated nanocatalystswithmesoporoussilica/silicateand microporous mofmaterials. Coord. Chem. Rev. 2016, 320-321, 181-192. [CrossRef]

13. Vivero-Escoto, J.L.; Slowing, I.I.; Trewyn, B.G.; Lin, V.S. Mesoporous silica nanoparticles for intracellular controlled drug delivery. Small 2010, 6, 1952-1967. [CrossRef] [PubMed]

14. Tang, F.; Li, L.; Chen, D. Mesoporous silica nanoparticles: Synthesis, biocompatibility and drug delivery. Adv. Mater. 2012, 24, 1504-1534. [CrossRef] [PubMed]

15. Karimi, M.; Mirshekari, H.; Aliakbari, M.; Sahandi-Zangabad, P.; Hamblin, M.R. Smart mesoporous silica nanoparticles for controlled-release drug delivery. Nanotechnol. Rev. 2016, 5, 195-207. [CrossRef]

16. Trewyn, B.G.; Giri, S.; Slowing, I.I.; Lin, V.S. Mesoporous silica nanoparticle based controlled release, drug delivery, and biosensor systems. Chem. Commun. 2007, 3236-3245. [CrossRef] [PubMed]

17. Kar, M.; Tiwari, N.; Tiwari, M.; Lahiri, M.; Gupta, S.S. Poly-L-arginine grafted silica mesoporous nanoparticles for enhanced cellular uptake and their application in DNA delivery and controlled drug release. Part. Part. Syst. Charact. 2013, 30, 166-179. [CrossRef]

18. Slowing, I.I.; Vivero-Escoto, J.L.; Wu, C.W.; Lin, V.S. Mesoporous silica nanoparticles as controlled release drug delivery and gene transfection carriers. Adv. Drug Deliv. Rev. 2008, 60, 1278-1288. [CrossRef] [PubMed]

19. Lu, J.; Liong, M.; Zink, J.I.; Tamanoi, F. Mesoporous silica nanoparticles as a delivery system for hydrophobic anticancer drugs. Small 2007, 3, 1341-1346. [CrossRef] [PubMed]

20. Lee, C.H.; Cheng, S.H.; Huang, I.P.; Souris, J.S.; Yang, C.S.; Mou, C.Y.; Lo, L.W. Intracellular pH-responsive mesoporous silica nanoparticles for the controlled release of anticancer chemotherapeutics. Angew. Chem. 2010, 49, 8214-8219. [CrossRef] [PubMed]

21. Lu, J.; Liong, M.; Li, Z.; Zink, J.I.; Tamanoi, F. Biocompatibility, biodistribution, and drug-delivery efficiency of mesoporous silica nanoparticles for cancer therapy in animals. Small 2010, 6, 1794-1805. [CrossRef] [PubMed]

22. He, Q.; Zhang, Z.; Gao, Y.; Shi, J.; Li, Y. Intracellular localization and cytotoxicity of spherical mesoporous silica nano- and microparticles. Small 2009, 5, 2722-2729. [CrossRef] [PubMed]

23. Kecht, J.; Schlossbauer, A.; Bein, T. Selective functionalization of the outer and inner surfaces in msn. Chem. Mater. 2008, 20, 7207-7214. [CrossRef]

24. Ma'mani, L.; Nikzad, S.; Kheiri-Manjili, H.; Al-Musawi, S.; Saeedi, M.; Askarlou, S.; Foroumadi, A.; Shafiee, A. Curcumin-loaded guanidine functionalized pegylated I3AD mesoporous silica nanoparticles KIT-6: Practical strategy for the breast cancer therapy. Eur. J. Med. Chem. 2014, 83, 646-654. [CrossRef] [PubMed] 
25. Lu, J.; Li, Z.; Zink, J.I.; Tamanoi, F. In vivo tumor suppression efficacy of mesoporous silica nanoparticles-based drug-delivery system: Enhanced efficacy by folate modification. Nanomed. Nanotechnol. Biol. Med. 2012, 8, 212-220. [CrossRef] [PubMed]

26. Zhang, Q.; Neoh, K.G.; Xu, L.; Lu, S.; Kang, E.T.; Mahendran, R.; Chiong, E. Functionalized mesoporous silica nanoparticles with mucoadhesive and sustained drug release properties for potential bladder cancer therapy. Langmuir 2014, 30, 6151-6161. [CrossRef] [PubMed]

27. Yuan, L.; Tang, Q.; Yang, D.; Zhang, J.Z.; Zhang, F.; Hu, J. Preparation of pH-responsive mesoporous silica nanoparticles and their application in controlled drug delivery. J. Phys. Chem. C 2011, 115, 9926-9932. [CrossRef]

28. Gulfam, M.; Chung, B.G. Development of pH-responsive chitosan-coated mesoporous silica nanoparticl. Macromol. Res. 2014, 22, 412-417. [CrossRef]

29. Zhu, M.; Zhu, Y.; Zhang, L.; Shi, J. Preparation of chitosan/mesoporous silica nanoparticle composite hydrogels for sustained co-delivery of biomacromolecules and small chemical drugs. Sci. Technol. Adv. Mater. 2013, 14, 045005. [CrossRef] [PubMed]

30. Zhao, Q.; Geng, H.; Wang, Y.; Gao, Y.; Huang, J.; Wang, Y.; Zhang, J.; Wang, S. Hyaluronic acid oligosaccharide modified redox-responsive mesoporous silica nanoparticles for targeted drug delivery. ACS Appl. Mater. Interfaces 2014, 6, 20290-20299. [CrossRef] [PubMed]

31. Gary-Bobo, M.; Mir, Y.; Rouxel, C.; Brevet, D.; Basile, I.; Maynadier, M.; Vaillant, O.; Mongin, O.; Blanchard-Desce, M.; Morère, A.; et al. Mannose-functionalized mesoporous silica nanoparticles for efficient two-photon photodynamic therapy of solid tumors. Angew. Chem. Int. Ed. 2011, 50, 11425-11429. [CrossRef] [PubMed]

32. Hu, L.; Sun, C.; Song, A.; Chang, D.; Zheng, X.; Gao, Y.; Jiang, T.; Wang, S. Alginate encapsulated mesoporous silica nanospheres as a sustained drug delivery system for the poorly water-soluble drug indomethacin. Asian J. Pharm. Sci. 2014, 9, 183-190. [CrossRef]

33. Trewyn, B.G.; Slowing, I.I.; Giri, S.; Chen, H.-T.; Lin, V.S.-Y. Synthesis and functionalization of a mesoporous silica nanoparticle based on the sol-gel process and applications in controlled release. Acc. Chem. Res. 2007, 40, 846-853. [CrossRef] [PubMed]

34. Hoffmann, F.; Cornelius, M.; Morell, J.; Froba, M. Silica-based mesoporous organic-inorganic hybrid materials. Angew. Chem. 2006, 45, 3216-3251. [CrossRef] [PubMed]

35. Huang, X.; Young, N.P.; Townley, H.E. Characterization and comparison of mesoporous silica particles for optimized drug delivery. Nanomater. Nanotechnol. 2014, 4, 2. [CrossRef]

36. Wang, Y.-J.; Pan, M.-H.; Cheng, A.-L.; Lin, L.-I.; Ho, Y.-S.; Hsieh, C.-Y.; Lin, J.-K. Stability of curcumin in buffer solutions and characterization of its degradation products. J. Pharm. Biomed. Anal. 1997, 15, 1867-1876. [CrossRef]

37. Salis, A.; Fanti, M.; Medda, L.; Nairi, V.; Cugia, F.; Piludu, M.; Sogos, V.; Monduzzi, M. Mesoporous silica nanoparticles functionalized with hyaluronic acid and chitosan biopolymers. Effect of functionalization on cell internalization. ACS Biomater. Sci. Eng. 2016, 2, 741-751. [CrossRef]

38. Rieger, A.M.; Nelson, K.L.; Konowalchuk, J.D.; Barreda, D.R. Modified annexin V/propidium iodide apoptosis assay for accurate assessment of cell death. J. Vis. Exp. 2011, 50, 2597. [CrossRef] [PubMed]

(C) 2017 by the authors. Licensee MDPI, Basel, Switzerland. This article is an open access article distributed under the terms and conditions of the Creative Commons Attribution (CC BY) license (http:/ / creativecommons.org/licenses/by/4.0/). 